\title{
Englacial water distribution in a temperate glacier from surface and borehole radar velocity analysis
}

\author{
Tavi Murray, ${ }^{1}$ Graham W. Stuart, ${ }^{2}$ Matt Fry, ${ }^{2}$ Nigola H. Gamble, ${ }^{1}$ Mike D. Crabtree ${ }^{1}$ \\ ${ }^{1}$ School of Geography, University of Leeds, Leeds LS2 977, England \\ ${ }^{2}$ School of Earth Sciences, University of Leeds, Leeds LS2 97T, England
}

\begin{abstract}
We have obtained common offset, common midpoint (CMP) and borehole vertical (VRP) ground-penetrating radar profiles close to the margin of Falljökull, a small, steep temperate valley glacier situated in southeast Iceland. Velocity analysis of CMP and VRP surveys provided a four-layered velocity model. This model was verified by comparison between the depths of englacial reflectors and water channels seen in borehole video, and from the depths of boreholes drilled to the bed. In the absence of sediment within the glacier ice, radar velocity is inversely proportional to water content. Using mixture models developed by Paren and Looyenga, the variation of water content with depth was determined from the radar velocity profile. At the glacier surface the calculated water content is $0.23-0.34 \%$ (velocity $0.166 \mathrm{~m} \mathrm{~ns}^{-1}$ ), which rises sharply to $3.0-4.1 \%$ (velocity $0.149 \mathrm{~m} \mathrm{~ns}^{-1}$ ) at $28 \mathrm{~m}$ depth, interpreted to be the level of the piezometric surface. Below the piezometric surface the water content drops slowly to $2.4-3.3 \%$ (velocity $0.152 \mathrm{~m} \mathrm{~ns}^{-1}$ ) until $\sim 102 \mathrm{~m}$ depth where it falls to $0.09-0.14 \%$ (velocity $0.167 \mathrm{~m} \mathrm{~ns}^{-1}$ ). The water content of the ice then remains low to the glacier bed at about $112 \mathrm{~m}$. These results suggest storage of a substantial volume of water within the glacier ice, which has significant implications for glacier hydrology, ice rheology and interpretations of both radar and seismic surveys.
\end{abstract}

\section{INTRODUGTION}

Most of our knowledge of the morphology of englacial water systems is based on theory and there are rather few direct observations, not least because of the difficulties of access. During the summer, surface melting of ice and snow, together with any rainfall, provides a more-or-less continual supply of surface water in the ablation zone. A small quantity of water can also be generated by englacial melting. Some water flows englacially through a connected system of veins or small-scale tubular features formed between the ice grains (Raymond and Harrison, 1975; Nye, 1989). These features are small, up to $2 \mathrm{~mm}$ in diameter (Raymond and Harrison, 1975), and may increase in size with depth (Shreve, 1972). Of far greater importance to water evacuation are moulins, which typically initiate where supraglacial streams intersect with surface crevasses (Lawson, 1993). These moulins are thought to be characterized by almost vertical shafts ending in splash pools linked by short sub-horizontal englacial channels (Holmlund, 1988). The water level in englacial channels will vary in response to changes in the basal water pressure, and the level to which such channels are full of water is the physical manifestation of the piezometric surface.

The englacial water distribution is important not only because of the role of englacial flow in glacier drainage (Fountain and Walder, 1998), but also because the water content of ice affects its physical properties. For example, increasing water content enhances ice strain rates by facilitating adjustment of grains with different orientations (Paterson, 1994). At constant applied stress and temperature, laboratory experiments suggest that the strain rate is linearly dependent on water content and triples between
$0.01 \%$ and $0.8 \%$ water content (Duval, 1977). Water content also affects radar and seismic propagation velocities, which are important for converting images to depth and placing reflectors in the correct geometric position (migration). It is often assumed for simplicity that there is a constant velocity of propagation (e.g. Fountain and Jacobel, 1997; Welch and others, 1998). This assumption will be incorrect if water content changes with depth or spatial location.

The velocity of radar signal propagation has been measured for cold ice to lie in the range $0.167-0.177 \mathrm{~m} \mathrm{~ns}^{-1}$ and to decrease with increasing water content in temperate ice (Bogorodsky and others, 1985). Such measurements have been used to estimate the bulk water content of warm ice (Macheret and others, 1993) and the variation of water content with depth in polythermal glaciers (Hamran and others, 1996). However, no corresponding measurements of the velocity and water-content profile have been made for temperate glaciers. The water content derived from radar wave velocities will be comprised of all water bodies that are small compared to the resolution of the radar, which is typically a few decimetres. Thus, such measurements will integrate the water content contained both in the vein network and in smaller channels and water-filled voids.

Radar-signal propagation velocity can be measured by: (i) comparison of surface radar-reflection profiles with drilling depths to the glacier bed (e.g. Robin and others, 1969); (ii) velocity analysis of common midpoint (CMP) or wide-angle reflection observations (e.g. Macheret and others, 1993); and (iii) direct measurement of signal travel times by lowering either a radar reflector or one or more radar antennae down a borehole (e.g. Robin, 1975; Jezek and Roeloffs, 1983). In this paper we use a combination of all of these methods to profile 
the variation in radar-signal velocity with depth in a temperate glacier. Control of the velocity model is provided by the depths of drillholes on the radar lines and the known depth of englacial features identified on borehole video. From these measurements we use standard dielectric ice/ water mixing formulae to develop a model of the watercontent profile for the glacier.

\section{FIELD SITE}

Falljökull is a $13 \mathrm{~km}$ long temperate glacier situated in southeast Iceland (Fig. 1). The glacier descends from a maximum altitude of $2119 \mathrm{~m}$ on the southern side of the Oræfajökull ice cap. At $5.5 \mathrm{~km}$ from the front of the glacier a $3 \mathrm{~km}$ long rock ridge splits the glacier into two steep and heavily crevassed ice-

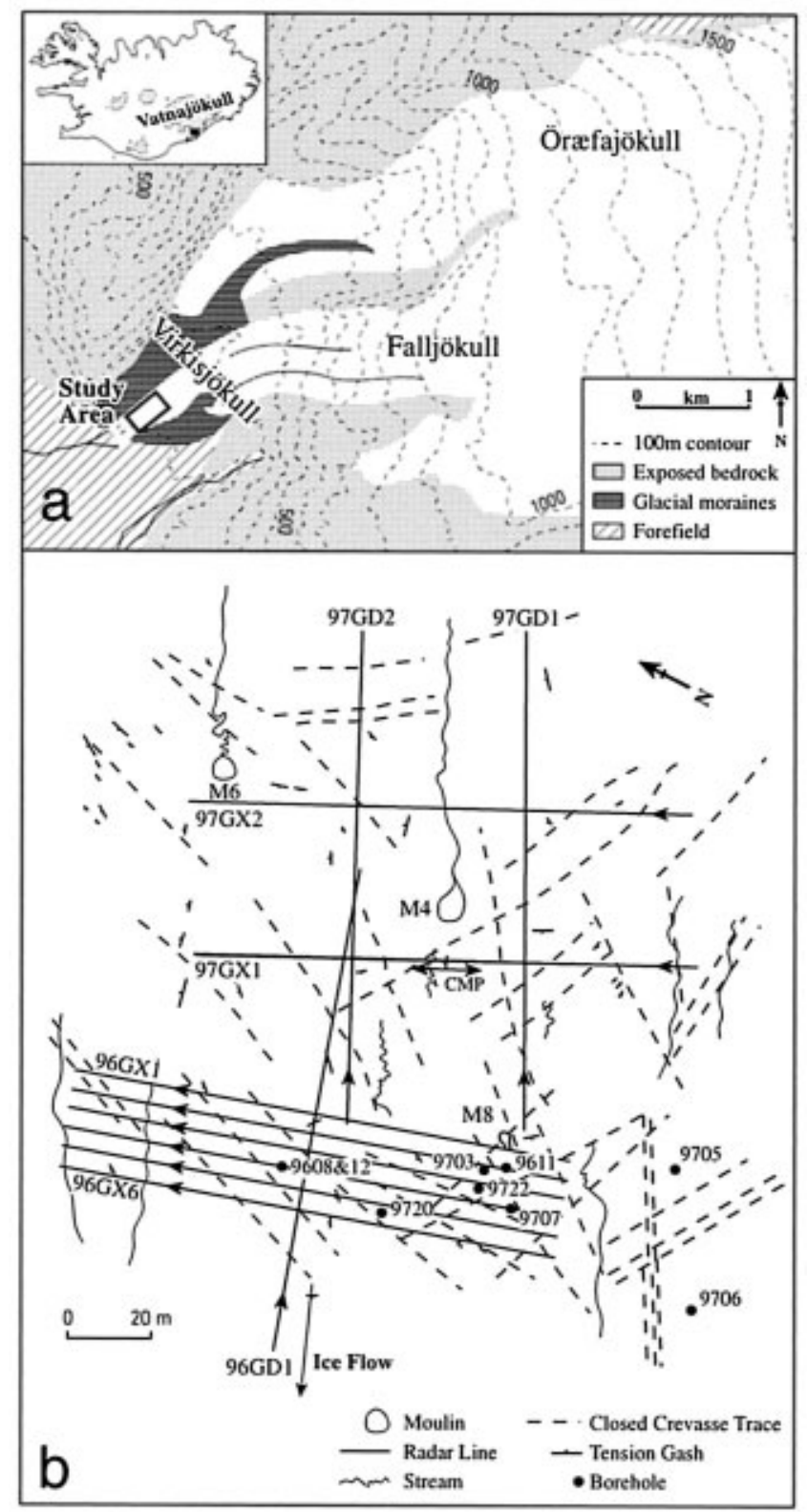

Fig. 1. (a) Map showing study site on Falljökull, southeast Iceland, and position of GPR survey lines below the icefall. In 1996, surveys were undertaken in early fune, and in 1997 during the first 3 weeks of $\mathrm{July}$. (b) Hydrological and structural features on the ice surface. M, moulin; CMP, centre of common midpoint survey. The borehole survey was undertaken in hole 9705. The survey direction of radar lines is shown by an arrow. falls. At the base of these icefalls, the crevasses close and the two tongues are separated by an ice-cored medial moraine. Based on hot-water drilling and penetration testing, Falljökull is thought to overlie patches of bedrock and decimetre-thick sediment (Crabtree, 1999). This bedrock is largely Upper Pleistocene basic and intermediate hyaloclastites and tuffaceous sediment overlain by basic and intermediate lava (Torfason, 1985). The glacier bed appears to be very rough, and adjacent boreholes $\sim 10 \mathrm{~m}$ apart often differ in depth by $\sim 5 \mathrm{~m}$.

Hot-water drilling, hydrological instrumentation and borehole video have been used to identify water-evacuation routes through the lower region of the glacier (Crabtree and Murray, 1996; Hiatt, 1998). The depths of boreholes together with the surveyed geometry of the glacier surface suggest that the glacier bed is overdeepened by $35-70 \mathrm{~m}$ below the icefall. This overdeepening is measured relative to a datum produced by extrapolating the mean slope of the proglacial valley through the altitude of the outlet stream. At Falljökull, in common with other glaciers with overdeepened beds (e.g. Hooke and Pohjola, 1994; Fountain and Walder, 1998), water evacuation is thought to occur mostly via englacial channels (Crabtree, 1999). Borehole video showed the existence of a large number of water-filled voids and small channels within the glacier ice (Hiatt, 1998). Furthermore, boreholes that did not intersect englacial channels, and which had no obvious supraglacial water source, often had water running down the borehole walls, the quantity of which appeared to increase with depth. These observations were interpreted to be evidence for vein or small-scale tubular drainage through the glacier ice (Hiatt, 1998). There is also evidence from drilling for larger-volume englacial drainage. Fifteen per cent of boreholes drilled (8 of 53) drained englacially at the time of drilling, and thus were connected to some form of larger-volume water-evacuation system (Crabtree, 1999).

\section{EQUIPMENT AND DATA COLLEGTION}

The data collected at Falljökull consisted of a series of common offset (CO) surveys, a CMP survey and a borehole survey sited close to the glacier margin (Fig. 1). In this paper we discuss only the results that lead to a velocity model for the propagation of electromagnetic radiation and its interpretation in terms of ice water content.

The radar used in this study was a PulseEKKO 100 ground-penetrating radar (GPR) system (Sensors and Software Inc., Mississauga, Canada) modified to record increased trace durations. Two borehole and surface antennae sets were available at nominal centre frequencies of 50 and $100 \mathrm{MHz}$. The sampling interval of $0.8 \mathrm{~ns}$ provided at least 12 samples per waveform cycle at $100 \mathrm{MHz}(25$ samples at $50 \mathrm{MHz}$ ). GPR systems are impulse transmitters, and the source waveform consisted of one-and-a-half cycles at the centre frequency. This waveform is a broadband signal containing energy at a wide range of frequencies.

The surveys were undertaken in the lower $0.3 \mathrm{~km}$ of the ablation zone below the icefall on the eastern part of the glacier (Fig. 1). At this location the ice-surface slope is approximately 8.5-10.5 ${ }^{\circ}$. During GPR surveying, the ice surface was clear of any snow and there was considerable surface melting. The location of all surface features that might be imaged by radar, such as supraglacial streams, closed crevasses, moulins and strong foliation, was noted (Fig. 1). 


\section{Surface surveys}

During surface (CO and CMP) surveys we recorded at discrete stations, and signals were stacked 128 times per trace. The survey lines were run with the antennae orientated perpendicular to the profile direction. This orientation minimizes reflections from offline because the radiation pattern has its widest energy footprint in the so-called H-plane, which is perpendicular to the antenna axis (Arcone, 1995; Arcone and others, 1995).

$\mathrm{CO}$ surveys are analogous to seismic reflection profiles and are used in this study as a control on the velocity determinations from borehole and CMP surveys. During these surveys the transmitter and receiver were mounted on a small sledge with the $50 \mathrm{MHz}$ antennae fixed $2 \mathrm{~m}$ apart. The station spacing was $0.5 \pm 0.05 \mathrm{~m}$.

CMP surveys are collected by progressively offsetting the transmitter and receiver symmetrically about a central point. Analysis of the resulting hyperbolic increases in travel times from near-horizontal reflectors at the CMP is a standard method of measuring the velocity of signal propagation and its variation with two-way travel time (twtt) or depth. Additional near-surface velocity information can be determined from the linear distance-time plot of the groundcoupled wave. A 120 m long CMP survey was undertaken in the cross-glacier direction in which surface and basal topography changes were expected to be smallest, and flat reflectors therefore most likely to occur. The line was centred at $60 \mathrm{~m}$ on $97 \mathrm{GX1}$ (Fig. 1). Antenna spacing increased at $0.5 \mathrm{~m}$ intervals. The survey used $50 \mathrm{MHz}$ antennae for maximum penetration.

\section{Borehole surveys}

Borehole surveys allow the direct measurement of velocity of propagation of the radar signal. Fewer assumptions are made during their interpretation than in the more widespread CMP surveys, and hence they allow direct testing of the velocity results of CMP surveys. Various types of borehole survey are possible; we undertook vertical radar profiles (VRPs) (analogous to vertical seismic profiles). Previous borehole studies have involved lowering a radar target down a borehole (e.g. Jezek and Roeloffs, 1983; Jezek, 1985) or used interferometric techniques (Robin, 1975). During our VRP surveys, the transmitting antenna was placed on the glacier surface, and the receiving antenna was lowered progressively down the borehole. This allowed us to measure the velocity in the vertical propagation direction, analagous to the velocities determined by CMP surveys.

The VRP survey reported in this paper used $100 \mathrm{MHz}$ antennae and was undertaken in borehole 9705 situated approximately $75 \mathrm{~m}$ from the centre of the CMP survey (Fig. 1). The borehole was water-filled at the time of surveying. The transmitter was located $5.5 \mathrm{~m}$ north of the borehole, the receiver was lowered down the borehole in $0.5 \mathrm{~m}$ steps and 64 traces were stacked at each depth. Due to the length of cable connecting the antenna to the receiver, the survey was limited to $30 \mathrm{~m}$ depth. This limitation meant that to extend the velocity information to the glacier bed $(\sim 110 \mathrm{~m})$ the results from borehole surveys must be combined with those from CMP surveys.

\section{Borehole video}

Based on initial radar results, boreholes were drilled using a hot-water drill at points of particular interest on radar lines 96GX2 and 96GX3. Three of these boreholes, 9608, 9611 and 9612 (Fig. 1), were then logged using a video camera based on the commercial oceanographic See-Snake system (Deep Sea Power and Light, San Diego, U.S.A.). The camera cable is marked every $2 \mathrm{~m}$ and the operator recorded the depth orally on the sound track each time a mark entered the borehole. The video was subsequently visually logged for crystallography, sediment content and the presence of englacial water bodies and channels, and used to correlate with reflection events on the CO surveys. Depths between marks have an estimated accuracy of better than $\pm 0.2 \mathrm{~m}$.

\section{DATA PROGESSING}

GRADIX software (version 1.10; Interpex Limited, 1996) was used for data processing and display of the surface GPR profiles. Initial processing included (i) high-pass filtering (2 $\mathrm{MHz}$ cut-off) to remove source-generated low-frequency noise (this process is commonly known as applying a dewow filter); (ii) setting the first arrivals to zero time; and (iii) automatic gain control (AGC) to amplify deeper reflections. $\mathrm{CO}$ lines were corrected for changes in elevation along the profile.

The processing parameters derived from rigorous testing on the CO surveys were applied to the CMP survey. Our approach was to test a set of zero-phase bandpass timedomain filters in order to observe the information content of the surveys at different centre frequencies. The CO surveys showed a low-frequency reflection arriving at 1300-1600 ns twtt on all lines when low-frequency bandpass filters with $<25 \mathrm{MHz}$ cut-off were used (Fig. 2). In general this lowfrequency reflector dipped towards the centre of the glacier

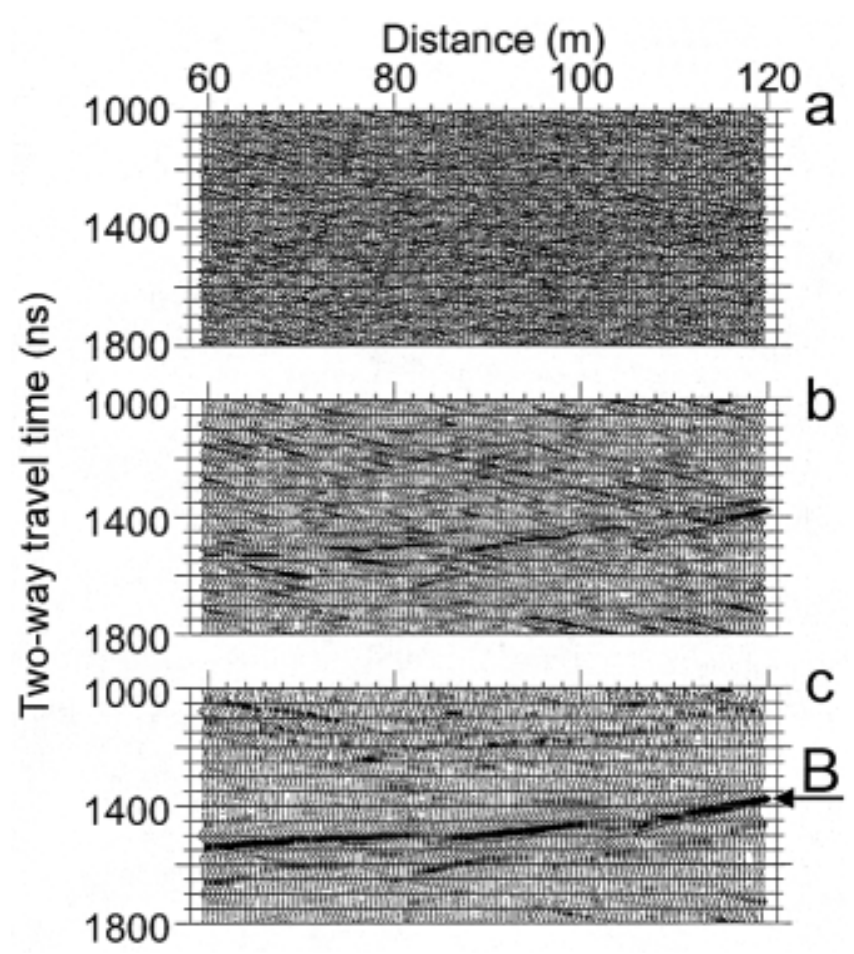

Fig. 2. GPR output from $50 \mathrm{MHz}$ CO line $97 \mathrm{GX} 2$ (see Fig. 1 for location), processed using (a) dewow and AGC function only. Additional processing used zero-phase Butterworth bandpass filters: (b) passband between 1 and $25 \mathrm{MHz}$; (c) passband between 1 and $10 \mathrm{MHz}$. Butterworth filters were eighth-order and sloped at $24 \mathrm{~dB} /$ octave to the $-3 \mathrm{~dB}$ (passband) frequencies. The low-frequency reflection at twott 1350-1500 ns (B) is interpreted to be the glacier bed. 
on cross-glacier lines (Fig. 2) and up-glacier on longitudinal lines, and the twtt to the reflector agreed within $\pm 15 \mathrm{~ns}$ at tie points between lines. The reflector varied in strength along lines, as would be expected if it represents the interface between ice and patchy till or bedrock. No coherent signal was evident below this reflector, suggesting either that little energy can penetrate below the interface or that no dielectric contrasts occur below it. We therefore interpreted this deep reflector as the glacier bed. This interpretation was subsequently supported by comparison of radar-derived and borehole depths. The CMP survey was then filtered using these optimized filters before semblance analysis.

Subsurface reflections on CMP surveys appear hyperbolic and their form is given by the normal move-out equation (Sheriff and Geldart, 1995, p. 85-86), provided the small-spread approximation holds: that is, that the depth to the reflector is very much greater than the distance between the antennae. The fit to a hypothetical hyperbolic trajectory calculated from the normal move-out equation can be measured by the semblance (Neidell and Taner, 1971). Semblance, $S_{\mathrm{T}}$, is the ratio of the total energy summed along the hyperbola within a given time interval, $\Delta t$, to the sum of the energy in the component traces within the same time interval and is calculated from

$$
S_{\mathrm{T}}=\frac{\sum_{t=t}^{t+\Delta t}\left(\sum_{i} x_{t i}\right)^{2}}{\sum_{t=t}^{t+\Delta t} \sum_{i}\left(x_{t i}\right)^{2}},
$$

where $x_{t i}$ is the amplitude of trace $i$ of the CMP survey at time $t$ (Neidell and Taner, 1971). The semblance is large when a coherent reflection is present, and is also sensitive to the amplitude of a reflection. The results of this analysis are usually presented as plots with $S_{\mathrm{T}}$ against velocity and travel time: a peak of semblance on the plot thus indicates the rootmean-square (rms) velocity for a particular travel time.

In this paper we use three types of velocity, namely, interval velocity, rms velocity and average velocity. The interval velocity is the velocity of a wave front through a single homogeneous layer. The rms velocity is the weighted rms of the layer interval velocities, with the weights determined by the layer thicknesses (Sheriff and Geldart, 1995, p. 92). The average velocity is the ratio of the distance travelled to the travel time.

\section{RESULTS}

\section{CMP surveys}

We analyzed the CMP data, in conjunction with the $\mathrm{CO}$ surveys (Fig. 3). Like the CO data, the unfiltered CMP data contain high-frequency clutter, which leads to false semblance peaks as well as those resulting from real reflections (Fig. 4). The filtered data allowed identification of real semblance peaks before the velocities in the unfiltered data were picked. The very high velocities seen on the semblance plots at twoway travel times greater than that generated by the glacier bed occur because of dipping or offline reflectors (Fig. 4). Either will result in false semblance highs at two-way travel times that are unrealistically long and velocities that are too fast. These semblance peaks were therefore ignored.

The results of semblance analyses following filtering (Fig. 4) were used to obtain the rms velocity of propagation to each reflector (Table 1). Eight estimates of the rms velocity were obtained at two-way travel times between $345 \mathrm{~ns}$ and the glacier bed at $1440 \mathrm{~ns}$. The interval velocity (Table 1) was then estimated using Dix's equation (e.g. Sheriff and Geldart, 1995, p. 130). The interval velocity was $0.160 \mathrm{~m} \mathrm{~ns}^{-1}$ at $345 \mathrm{~ns}$, fell sharply to $0.149 \mathrm{~m} \mathrm{~ns}^{-1}$ between this twtt and $380 \mathrm{~ns}$, and then rose progressively to $0.167 \mathrm{~m} \mathrm{~ns}^{-1}$ at the bed. Further control came from the comparison of depths calculated from the rms velocity to the glacier bed $\left(0.156 \mathrm{~m} \mathrm{~ns}^{-1}\right)$ and measured depths of boreholes. The depth of boreholes drilled within $10 \mathrm{~m}$ of the radar lines (Fig. 1) agrees with the depth of the reflector interpreted as the glacier bed to $\pm 7 \mathrm{~m}$. The linear ground-coupled wave travelling in the surface ice was picked on the CMP survey and gave a velocity of $0.166 \pm 0.001 \mathrm{~m} \mathrm{~ns}^{-1}$ (Fig. 3).

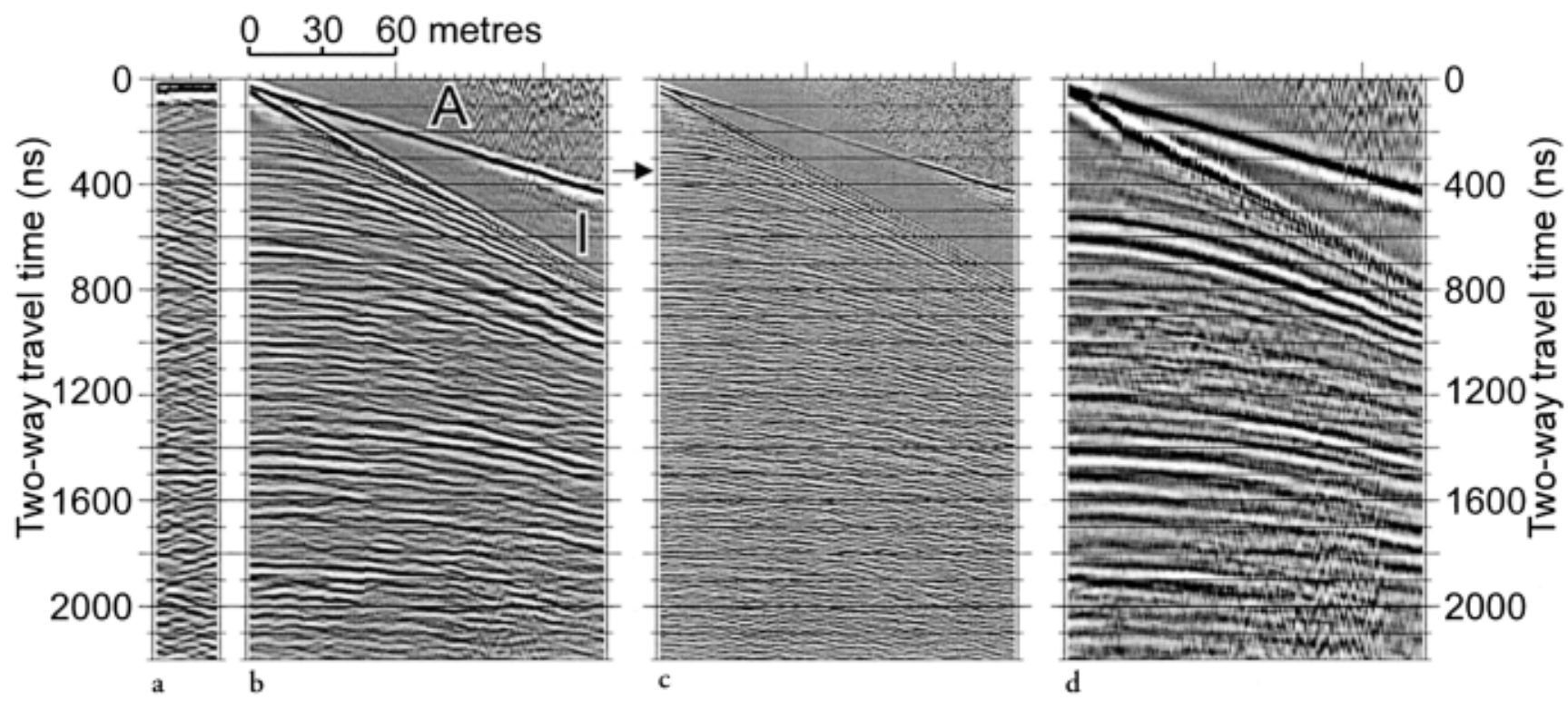

Fig. 3. Results of $50 \mathrm{MHz}$ cross-glacier CMP survey ( see Fig. 1 for location) displayed with an AGC function of 500 ns length. Arrow marks location of abrupt change in interval velocity interpreted to be the piezometric surface. (a) Corresponding section of the $50 \mathrm{MHz}$ CO line $97 \mathrm{GX1}$. (b) CMP dewowed and filtered using $25 \mathrm{MHz}$ filter. A, airwave (velocity $0.298 \pm 0.001 \mathrm{~m} \mathrm{~ns}^{-1}$ ); I, ground-coupled wave (velocity $0.166 \pm 0.001 \mathrm{~m} \mathrm{~ns}^{-1}$ ). (c) CMP dewowed but unfiltered. (d) CMP dewowed and filtered using $10 \mathrm{MHz}$ filter. Details of filters are given in Figure 2 caption. 
a RMS velocity spectrum $\left(m \mathrm{~ns}^{-1}\right)$

\section{b}

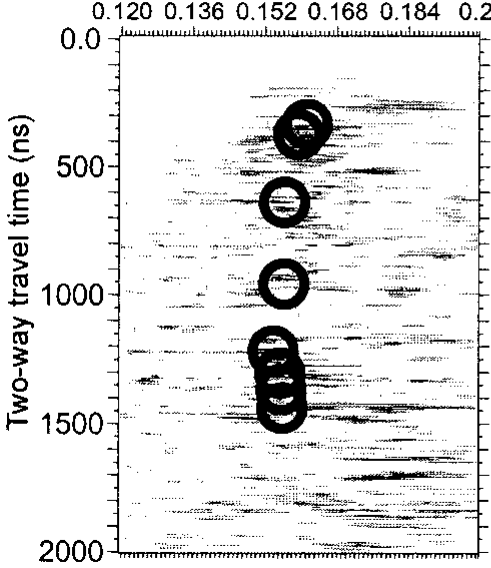

b Peak semblance

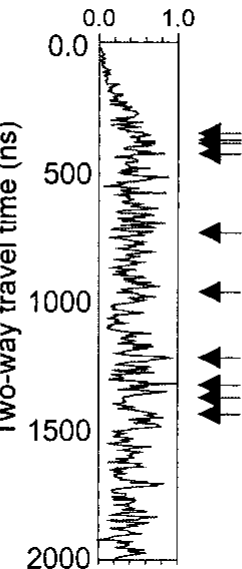

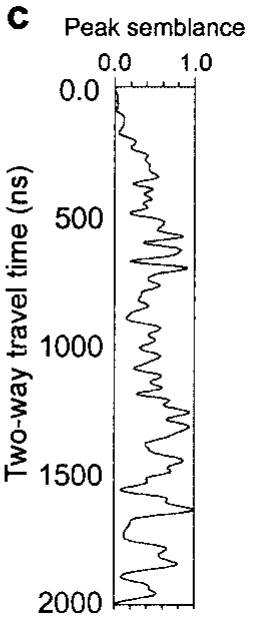

d Peak semblance

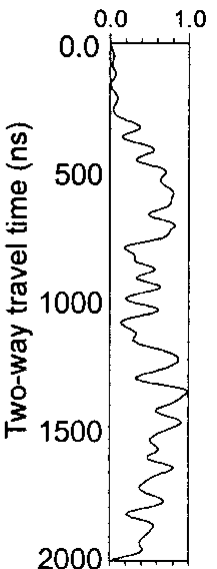

Fig. 4. Semblance plots from $50 \mathrm{MHz}$ cross-glacier CMP survey. (a) Velocity spectrum from dewowed but otherwise unfiltered data (see Fig. 1 for location). Semblance values are plotted from lowest (white) to highest (black). (b) Peak semblance for dewowed unfiltered data. (c) Peak semblance for data dewowed and filtered using $25 \mathrm{MHz}$ filter. (d) Peak semblance for data dewowed and filtered using $10 \mathrm{MHz}$ filter. Filter details are given in Figure 2 caption. Black circles and arrows in $(a)$ and (b) show the semblance highs that were used in this analysis (Table 1).

Table 1. Final model for interval velocity variation with depth from combined VRP and CMP results

\begin{tabular}{|c|c|c|c|c|}
\hline $\begin{array}{l}\text { Twett to } \\
\text { reflector }\end{array}$ & Depth & $\begin{array}{c}\text { Rms velocity } \\
\text { from CMP survey }\end{array}$ & $\begin{array}{l}\text { Modelled interval } \\
\text { velocity }^{\dagger}\end{array}$ & Layer \\
\hline $\mathrm{ns}$ & $\mathrm{m}$ & $\mathrm{mns}^{-1}$ & $\mathrm{mns}^{-1}$ & \\
\hline 345 & 27.6 & 0.160 & $\begin{array}{c}\text { As VRP results } \\
\text { (Fig. 5b) }\end{array}$ & $\begin{array}{c}1 \text { (as VRP } \\
\text { results) }\end{array}$ \\
\hline 380 & 30.2 & 0.159 & 0.149 & 2 \\
\hline 420 & 33.2 & 0.158 & 0.149 & \\
\hline 603 & 47.0 & 0.156 & 0.151 & \\
\hline 915 & 70.5 & 0.154 & 0.151 & \\
\hline 1220 & 93.9 & 0.154 & 0.154 & 3 \\
\hline 1320 & 102.3 & 0.155 & 0.167 & 4 (to bed) \\
\hline 1440 & 112.3 & 0.156 & 0.167 & \\
\hline
\end{tabular}

${ }^{*} \pm 10$.

${ }^{\dagger} \pm 0.001$.

\section{Borehole radar surveys}

The first breaks from VRP surveys were picked at $5 \%$ of the maximum trace amplitude (Fig. 5a). We assume that the first break corresponds to energy with a straight-line propagation path through the glacier ice. Travel distances between transmitter and receiver were corrected for the offset between the transmitter and borehole, and interval velocities were then calculated using a seven-point average least-squares fit to the gradient of the resulting time--distance plot. The VRP survey indicated that interval velocity varies with depth between 0.147 and $0.172 \mathrm{~m} \mathrm{~ns}^{-1}$ (Fig. 5b). Rms velocities were calculated from these interval velocities to compare with the CMP survey, and varied from $0.167 \mathrm{~m} \mathrm{~ns}^{-1}$ at the surface (cf. $0.166 \mathrm{~m} \mathrm{~ns}^{-1}$ derived from the CMP ground-coupled wave), dropping to $0.151 \mathrm{~m} \mathrm{~ns}^{-1}$ at $2.5 \mathrm{~m}$ and gradually rising to $0.162 \mathrm{~m} \mathrm{~ns}^{-1}$ at $26.5 \mathrm{~m}$ depth.

The largest component of error in these calculations is the a

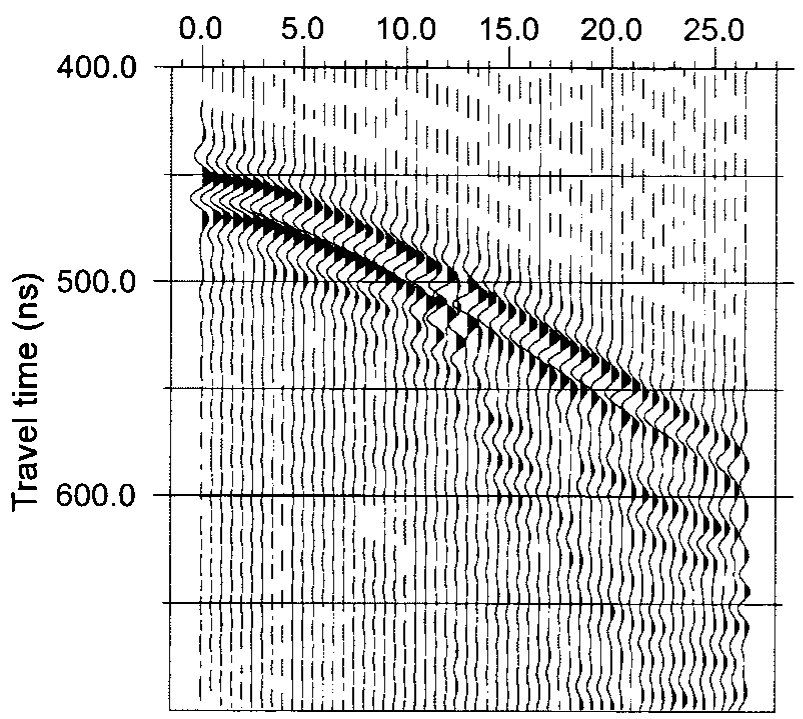

b

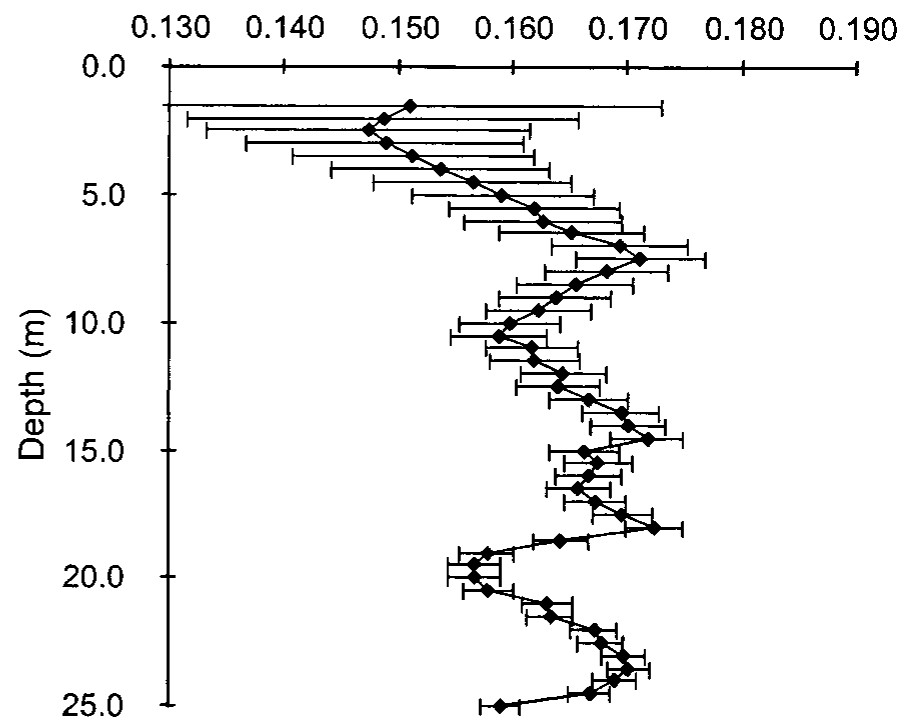

Fig. 5. Results of $100 \mathrm{MHz}$ VRP survey at borehole 9705 . The transmitter was placed $5.5 \mathrm{~m}$ from the borehole. (a) GPR output. Signals have been dewowed. (b) Interval velocity vs depth profile using seven-point average least-squares fit to VRP results. 
deviation of the true geometry of the borehole from vertical. Errors resulting from picking and antennae placement are considered to be negligible in comparison. The boreholes were drilled using standard hot-water drilling techniques. In the absence of inclinometric measurements, we calculate the error in the velocity by assuming a maximum $5^{\circ}$ deviation of the borehole from vertical. This is less than the maximum deviation quoted by Copland and others (1997) from a study of deep boreholes at Haut Glacier d'Arolla, Switzerland, drilled using similar techniques, but is $2-3^{\circ}$ larger than their maximum error at $30 \mathrm{~m}$ depth, which is the depth limit on our borehole radar. The error shown in Figure 5 decreases with depth because of the increased path length between the antennae.

\section{Velocity-depth profile}

The detailed but shallow velocity information from the borehole survey needs to be integrated with the CMP results which extend to the glacier bed. The velocities estimated from CMP surveys are interval velocities calculated from rms velocities, whereas those resulting from VRP surveys are interval velocities calculated from vertical travel times. We assume that interval velocities calculated from these two types of measurements can be directly equated. The deepest antenna during the borehole VRP surveys at $26.5 \mathrm{~m}$ gave an average velocity from the surface of $0.162 \mathrm{~m} \mathrm{~ns}^{-1}$. The first rms velocity of the GMP survey, which is equivalent to the average velocity in the first layer, was $0.160 \mathrm{~m} \mathrm{~ns}^{-1}$. This value was determined at a $345 \mathrm{~ns}$ twtt or $27.6 \mathrm{~m}$ depth (Table 1). Thus, there is good agreement between the deepest VRP estimates of velocity and the shallowest velocity from the CMP surveys, despite the different locations of the two surveys (Fig. 1). Furthermore, the depth measured to the channels seen on the borehole video and the reflector on the corresponding $\mathrm{CO}$ line (Figs 6 and 7) can be used to calculate an independent velocity estimate of $0.157-0.162 \mathrm{~m} \mathrm{~ns}^{-1}$ at $370 \mathrm{~ns}$ twtt, which is consistent with the velocity from the CMP survey (Table 1). These observations suggest that lateral variations are small compared to vertical variations within the surveyed region, and therefore that the GMP and VRP surveys can be combined in a single velocity model for this region of the glacier.

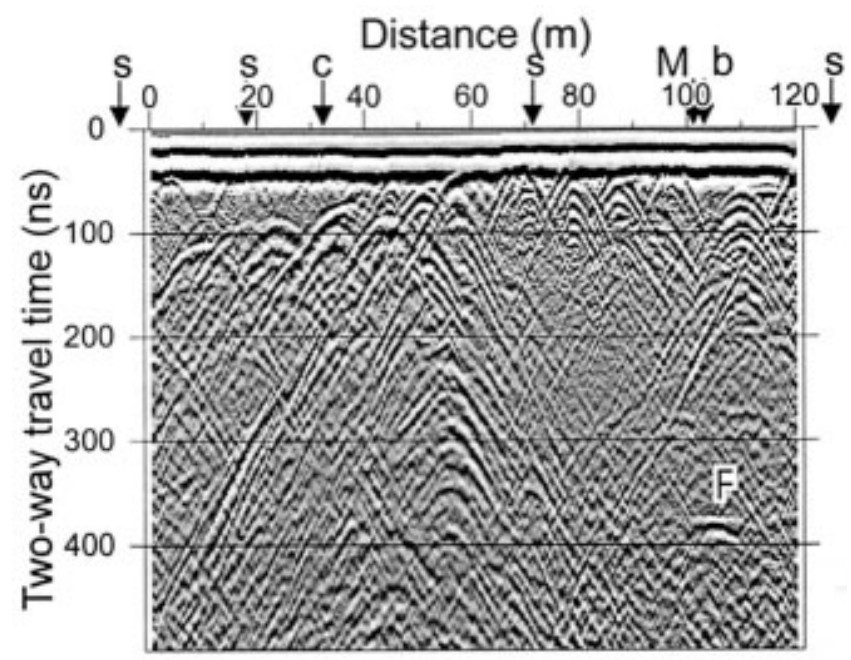

Fig. 6. $50 \mathrm{MHz}$ GPR CO line 96GX2, processed using dewow and AGC function (see text for details). F, feature corresponding to a series of active channels located on borehole video. The positions of surface features on the line that may cause interference are marked: s, stream; $M$, moulin; b, borehole; c, crevasse.

\section{DISGUSSION}

\section{Velocity models}

A layered model of interval velocity with depth was developed that incorporated the results of both the VRP and CMP surveys. The developmental criteria were: (i) a simple

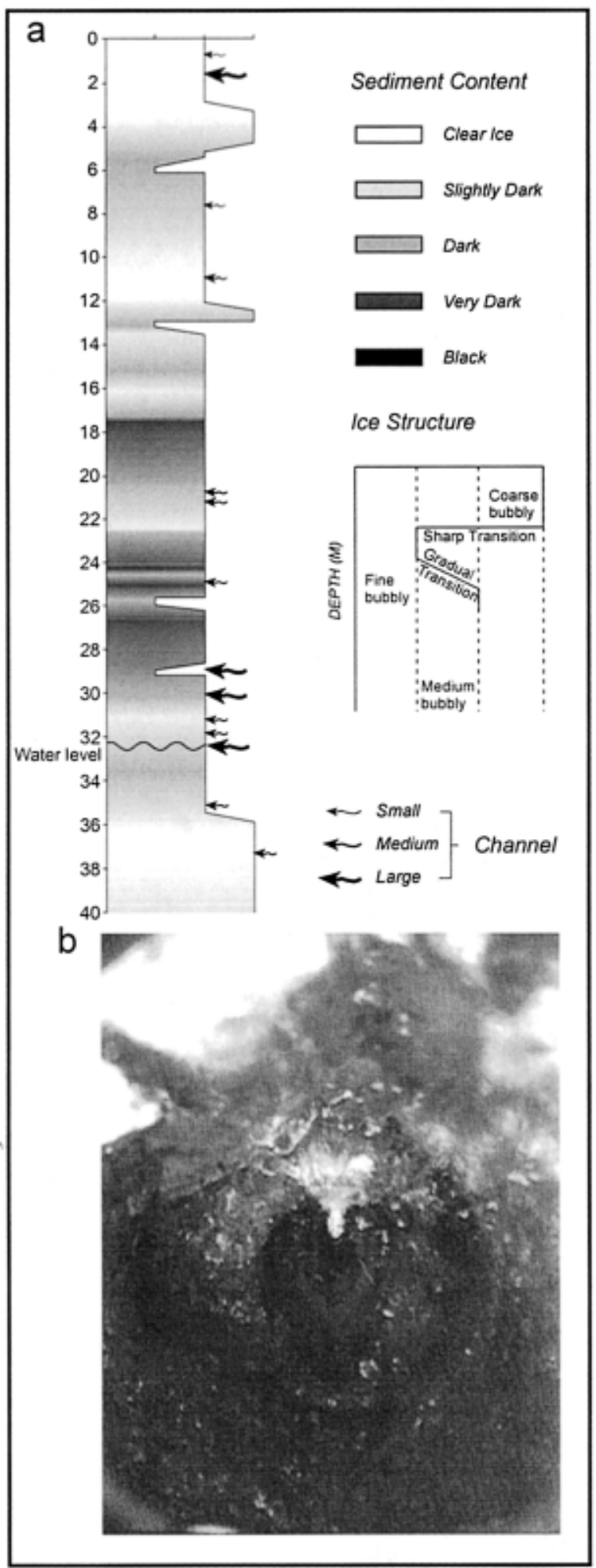

Fig. 7. Results from video from borehole (9611) on line 96GX2. (a) Schematic logs of water bodies. (b) Frame grab of one of a series of channels at 29-32 $m$ thought to cause reflection $F$ in Figure 6 at 10-22 $\mathrm{m}$ along the line at approximately $370 \mathrm{~ns}$ twtt. Water can be seen entering the borehole from the channel in the centre of the frame at a height of approximately twothirds the frame height. 
model was preferred, with the lowest number of layers needed to explain the data; (ii) a model with smooth variations in velocity was preferred over one that oscillated between fast and slow velocities at each layer in order to fit the data. The final velocity model (Table 1) has four layers. The surface velocity was taken from the velocity of the ground-coupled wave, $0.166 \pm 0.001 \mathrm{~m} \mathrm{~ns}^{-1}$, and the velocity in the upper $26.5 \mathrm{~m}$ from the VRP survey (layers la and lb; Fig. 5b). The CMP survey then indicated a sharp drop in interval velocity from 0.160 to $0.149 \mathrm{~m} \mathrm{~ns}^{-1}$ between 345 and $380 \mathrm{~ns} \mathrm{twtt} \mathrm{(layer}$ 2), followed by a more gradual rise at greater depth (layer 3). The sharp change in interval velocity results in a reflection coefficient of -0.04 and hence would result in a very weak reflection. The temporal location of such a reflection is shown in Figure 3. Layer 3 continues down to 1220 ns where velocity increases to $0.167 \mathrm{~m} \mathrm{~ns}^{-1}$ (layer 4), which is the velocity calculated for ice between here and the glacier bed at $1440 \mathrm{~ns}$. The abrupt changes in velocity at layer boundaries (Table 1) are probably artificial, and a more gradual variation as shown in Figure 8 is likely to be more representative of the real situation.

These velocities calculated for Falljökull are lower than those typically given for cold glacier ice. However, the velocity of electromagnetic radiation in temperate ice is known to decrease with increasing water content of the ice (Macheret and others, 1993). For example, velocities of 0.138 and $0.159 \mathrm{~m} \mathrm{~ns}^{-1}$ are quoted for temperate glaciers in the Western Alps (Nicollin and others, 1992) and New Zealand (Nobes and others, 1994), respectively.

\section{Estimates of water content}

If glacier ice is assumed to be a two-component mixture with random inclusions of water with characteristic dimensions much less than the radar-signal wavelength, then the

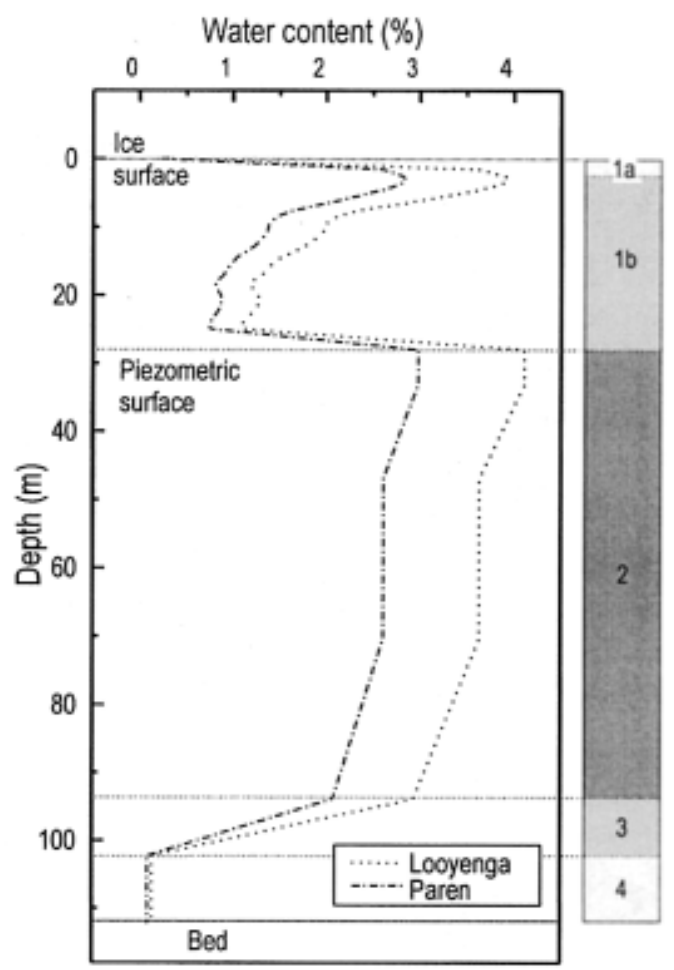

Fig. 8. Best model of water content vs depth using combined borehole and CMP results. The bar on the right shows the water content conceptually; shading increases in intensity with increasing water content. velocity-depth profile presented (Fig. 5b; Table 1) can be considered equivalent to a water-content-depth profile. The radar velocity of ice with randomly distributed linear water inclusions can be modelled using Paren's mixture formula. This relates the fractional water content, $n$, to the relative dielectric permittivities of dry glacier ice, $\varepsilon_{\mathrm{i}}$, and water, $\varepsilon_{\mathrm{w}}$, the speed of electromagnetic radiation in free space, $c$, and the measured speed of propagation through the wet ice, $v$ :

$$
n=\frac{3}{\varepsilon_{\mathrm{w}}}\left(\frac{c^{2}}{v^{2}}-\varepsilon_{\mathrm{i}}\right)
$$

(Paren, 1970; Smith and Evans, 1972). An alternative approach is to consider the inclusions to be randomly distributed spherical bodies. In this case the Looyenga mixture formula can be used:

$$
n=\frac{(c / v)^{2 / 3}-\varepsilon_{\mathrm{i}}^{1 / 3}}{\varepsilon_{\mathrm{w}}^{1 / 3}-\varepsilon_{\mathrm{i}}^{1 / 3}}
$$

(Looyenga, 1965; Macheret and others, 1993). The estimate of water content using the Looyenga mixture formula (Equation (3)) is always greater than that using Paren's mixture formula (Equation (2)). In subsequent discussion each water content quoted will be calculated from Paren's mixture formula followed in parentheses by that calculated using the Looyenga mixture formula.

The water-content-depth model is presented in Figure 8. It assumes that other factors known to change the electrical properties of ice, such as the presence of air bubbles, chemical impurities, debris or crystal orientation (e.g. Paterson, 1994), do not change with depth at this glacier. The velocity of propagation at the glacier surface is $0.166 \mathrm{~m} \mathrm{~ns}^{-1}$, which is equivalent to a water content of $0.23 \%(0.34 \%)$. The borehole-survey results then suggest the water content rises slowly and falls again as the velocity rises towards $26 \mathrm{~m}$ depth. The sharp fall in velocity to $0.149 \mathrm{~m} \mathrm{~ns}^{-1}$ at $28 \mathrm{~m}$ below the surface corresponds to water content rising to $3.0 \%(4.1 \%)$. Between 28 and $33 \mathrm{~m}$ depth the velocity is $0.149 \mathrm{~m} \mathrm{~ns}^{-1}$, rising to $0.151 \mathrm{~m} \mathrm{~ns}^{-1}$ at $33 \mathrm{~m}$, corresponding to a drop in water content to $2.1 \%(2.9 \%)$ between 33 and $102 \mathrm{~m}$. Between $102 \mathrm{~m}$ and the glacier bed the velocity is $0.167 \mathrm{~m} \mathrm{~ns}^{-1}$, and corresponding water content $0.09 \%(0.14 \%)$. The depthaveraged water content for the entire thickness of the glacier is $1.74 \%(2.48 \%)$. The depth-averaged value at Falljökull is similar to the water content of Abramov glacier in the Altai mountains, central Asia, calculated as $1.27 \%$ (1.69\%) averaged over the ice column in the ablation area and $1.61 \%$ $(2.16 \%)$ for warm ice in the accumulation zone (Macheret and others, 1993).

The rapid decrease in velocity at $28 \mathrm{~m}$ is attributed to an increase in water content to $3.0 \%(4.1 \%)$, although an alternative explanation would be a rapid increase in sediment content within the glacier ice (e.g. Murray and others, 1997). We cannot differentiate between these two possibilities on the basis of the velocity contrast across this boundary, because both would result in an increase in permittivity (Arcone and others, 1995). However, the logs of video from boreholes 9611 and 9612 do not support the presence of sediment at this depth (Fig. 7). The water level within voids and channels that are connected to the glacier bed will vary as a result of changes in basal water pressure. Borehole water-pressure measurements show mean water pressure to be equivalent to a water surface at $28.5 \mathrm{~m}$ below the glacier surface on one pressure sensor and at $36.5 \mathrm{~m}$ on a second pressure sensor 
during the period following the GPR surveys (Crabtree, 1999). Diurnal fluctuations in pressure were small, typically $<10 \mathrm{~m}$ (Crabtree, 1999). These observations, together with the continuing high water content of ice below $28 \mathrm{~m}$ level to $>90 \mathrm{~m}$, suggests that the increase in water content at $28 \mathrm{~m}$ most likely represents a physical manifestation of the piezometric surface. Layer 2 might alternatively represent the depth of a significant number of englacial channels or a concentration of water-filled voids (Jacobel and Anderson, 1987; Hooke and Pohjola, 1994), with fewer forming in the surface ice (layer 1) or in the deepest ice (layers 3 and 4), but this is deemed less likely. The top of layer 2 is marked by only a weak reflector, in stark contrast to the strong reflection seen from an englacial channel ( $F$ in Fig. 6). This contrast suggests that the interface at the top of layer 2 is rougher or more diffuse than seen at channel features.

The water-content model we have produced for Falljökull shows an essentially four-layered structure (Fig. 8), although the propagation velocity measured, and hence water content inferred, is expected to vary continuously through the profile rather than in steps. The surface ice (layer la) has a high velocity, typical of that reported for cold ice, and is thought to have a high porosity and low water content. It is likely that this ice is well drained (cf. Fountain and Walder, 1998). Within a few metres of the surface the ice becomes wetter (layer lb). A sharp fall in propagation velocity and hence rise in water content at $28 \mathrm{~m}$ depth (layer 2) to $3.0 \%$ (4.1\%) is inferred to be the piezometric surface of the glacier. This implies that there must be sufficient void space within the ice that is connected to the basal water system and which can act as a manometer reacting to changes in basal water pressure. Below the piezometric surface, this wetter ice is underlain by two layers of progressively lower-water-content ice (layers 3 and 4).

While profiles of water content for temperate glaciers are generally lacking in the literature, several authors have produced models for the water content of subpolar glaciers from combinations of the presence of internal reflecting horizons, radar velocity measurements or thermistor measurements (e.g. Macheret and others, 1993; Jania and others, 1996). These models vary in the number of layers they distinguish, from simple two-layer models (e.g. Bamber, 1987) to four-layer models that identify both the cold-warm ice boundary and the level of the piezometric surface within the glacier (Jania and others, 1996). The more complex of these models show marked similarities to the model we have developed for the ice profile at Falljökull. At Hansbreen, a polythermal glacier in Svalbard, Jania and others (1996) developed a four-layer model that suggests that the cold surface ice (absent at Falljökull) is underlain by a 20-40 m thick layer of warm ice with a low water content (equivalent to our layer 1). The piezometric surface delineates the top of a $60 \mathrm{~m}$ thick layer of warm ice with water content of 4-5\% (equivalent to our layer 2 ) which is underlain by a further low-water-content layer close to the glacier bed (Jania and others, 1996), equivalent to our layers 3 and 4. The high-water-content layer at Hansbreen was also identified by Macheret and others (1993), although they suggested that the values were anomalously high and probably resulted from a concentration of water-filled channels and cavities within the ice column (Macheret and others, 1993).

The water contents inferred from measurement of the propagation velocity of electromagnetic radiation appear to be higher than those measured on ice cores from temperate ice, which are typically $0.1-1 \%$ at maximum (e.g. Raymond and Harrison, 1975; Vallon and others, 1976). Our measure- ments suggest that at Falljökull the wettest ice has a water content of $3.0-4.1 \%$. Measurements by methods that are fundamentally similar give values that are similar for warm ice at other sites. For example, Bamber (1987) gives a value of $>3 \%$ for the wettest ice layer at a number of Svalbard glaciers using the Looyenga mixture fomula (Equation (3)). Macheret and others (1993) calculate 4-5\% for ice at Hansbreen using both the Looyenga and Paren's mixture formulae (Equations (2) and (3)).

Assuming that the dielectric mixing formulae used are valid, the most obvious difference between the radar and ice-core measurements is that the radar measurements are averaging over a much greater sample volume. Water bodies that were large with respect to some fraction of the core diameter (the core would be incomplete or structurally unsound if large water bodies were sampled) but small compared to the resolution of the radar might be poorly sampled by coring techniques: the radar resolution is equal to onequarter of the radar wavelength, $\lambda(\lambda / 4$ is equal to $0.84 \mathrm{~m}$ at $50 \mathrm{MHz}$ or $0.42 \mathrm{~m}$ at $100 \mathrm{MHz}$ in cold ice (Sheriff and Geldert, 1995, p. 172-175)). To produce ice with the water content we infer at Falljökull, 7-10 spherical water bodies of $0.1 \mathrm{~m}$ radius are required per cubic metre, or $780-1000$ of $0.01 \mathrm{~m}$ radius, assuming that there is no water in the vein system or in other inclusions. We therefore postulate that the existence of centimetre- to decimetre-scale water bodies may explain the difference between the two types of measurements. Borehole video observations at Falljökull (Hiatt, 1998) and elsewhere (Pohjola, 1994) support the existence of such voids in temperate ice: at Storglaciären they are estimated to provide an apparent void ratio of $\sim 1.3 \%$ (Pohjola, 1994).

Theoretical considerations suggest that the water content of ice should increase with depth due to the increased heat released by ice deformation (Vallon and others, 1976), and indeed this trend was seen at Uvérsbreen (Hamran and others, 1996). However, we observe the opposite trend at Falljökull (layers 3 and 4). Furthermore, measurements on a core taken in the French Alps show decreasing water content close to the bed (Vallon and others, 1976). The presence of these layers with decreasing water content at Falljökull could be due to a progressive reduction in the presence of small connected voids in the glacier available to be filled by the water system due to (i) the expected arborescent nature of the water system with depth tending to localize water in discrete channels, and (ii) an increased rate of closure of voids at depth due to higher normal and shear stresses, and hence ice-deformation rates.

There are a number of important implications of these results:

(1) The large variations in water content will create layers of softer ice within the glacier. While some of the englacial water is probably contained within small pockets of water rather than at grain boundaries, any water within the ice structure enhances sliding between grains and softens the ice. At constant temperature and applied stress the strain rate is increased by $\sim 3.8$ times for each $1 \%$ increase in water content (Duval, 1977). We suggest that the bulk ice water content at Falljökull can be as high as $3-4 \%$ or as low as $0.1 \%$. Extrapolation of Duval's results would suggest the wettest ice could be up to $11-15$ times softer than the driest ice.

(2) The water-content profile shows a sharp increase at $28 \mathrm{~m}$ depth from $0.23-0.34 \%$ to $3.0-4.1 \%$. We interpret this increase as marking the level of the piezometric surface. 
There must therefore be sufficient connected void space within the glacier for the ice bulk water content to react to basal water pressure. At the time of our survey this void space was storing substantial volumes of water. Fountain and Walder (1998) calculate that for a $100 \mathrm{~m}$ thick glacier a macroporosity of only $0.1 \%$ in hydraulic communication with the basal water system is equivalent to a $0.1 \mathrm{~m}$ thick layer of water stored at the bed. They further suggest that this could be important in storing the early-season excess of meltwater. Our water-content profile suggests the ice at Falljökull has a substantially higher water content. Our model layer 2 contains the water equivalent of a layer at least $1.8 \mathrm{~m}$ thick at the glacier base.

(3) The high water content in temperate ice substantially reduces the velocity of radar propagation from that of cold ice. Studies where a cold-ice velocity is used to calculate the depth of temperate ice may be in error. Using a cold-ice velocity $\left(0.168 \mathrm{~m} \mathrm{~ns}^{-1}\right)$ rather than our depthaveraged velocity $\left(0.156 \mathrm{~m} \mathrm{~ns}^{-1}\right)$ would result in overestimating the glacier depth by $\sim 7 \%$.

(4) The rapid variation in water content with depth we observe suggests that refraction of radar signals is likely. This means that assumptions of straight-line travel for radar surveys may be invalid. Such variation also requires caution when calculating the depth to englacial features on radar profiles.

(5) Interpretation of radar profiles requires migration to place reflectors in their correct geometric position. This geometric correction depends on the radar propagation velocity, typically taken as a constant value (e.g. Fountain and Jacobel, 1997; Welch and others, 1998). Our results suggest that the velocity varies with depth, and therefore that a layered model is required.

(6) The velocity of P- and S- waves in temperate ice depends sensitively on the amount of liquid water at grain boundaries (Röthlisberger, 1972). Thus our results and cautions will apply not only to radar but also to seismic surveys of temperate glaciers.

\section{GONCLUSIONS}

GPR has been used to derive a bulk water-content-depth profile in the accumulation zone of the temperate glacier Falljökull, imaging those components of the water system that are smaller than the resolution of the radar. Semblance analysis of CMP surveys filtered at frequencies of $<25 \mathrm{MHz}$ allowed calculation of the velocity of propagation at depths at which coherent returns were observed. Combining the results of the CMP surveys with borehole surveys provided several velocity determinations at depths down to the glacier bed. Since there is little sediment in the glacier ice, we interpret this velocity to represent water content. There are strong similarities between our model for water content at Falljökull, which is a temperate glacier, and models developed for subpolar glaciers elsewhere. In particular, features of our model are (i) low water content at the glacier surface $(0.23-0.34 \%)$, (ii) a sharp increase in high water content to $3.0-4.1 \%$ at $28 \mathrm{~m}$ depth, and (iii) decrease in water content to $0.09-0.14 \%$ close to the glacier bed. The results have implications for water storage and transport, for ice rheology and for the interpretation of geophysical surveys.

\section{ACKNOWLEDGEMENTS}

This research was funded by the U.K. Natural Environment Research Council (NERG) (GR3/R9613) and SUPERSLUGS research initiative at the School of Geography, University of Leeds. Grants from the Academic Development Fund and the School of Geography, University of Leeds, funded the University of Leeds GPR and borehole camera systems. P. Annan (Sensors and Software Inc.) kindly loaned the borehole antennae. M. Fry was funded by an NERC Advanced Course Studentship, N. Gamble by a White Rose Scholarship, and M. Crabtree by a SUPERSLUGS studentship. We thank the Research Council of Iceland for permission to work at Falljökull. S. Fuller, T. Dion, A. Hiatt and P. Porter helped with the fieldwork. This paper was significantly improved by the constructive reviews of J. Walder, R. Jacobel and an anonymous reviewer.

\section{REFERENGES}

Arcone, S. A. 1995. Numerical studies of the radiation patterns of resistively loaded dipoles. F. Appl. Geophys., 33(1-3), 39-52.

Arcone, S. A., D. E. Lawson and A. J. Delaney. 1995. Short-pulse radar wavelet recovery and resolution of dielectric contrasts within englacial and basal ice of Matanuska Glacier, Alaska, U.S.A. F. Glaciol., 41(137), 68-86.

Bamber, J. L. 1987. Internal reflecting horizons in Spitsbergen glaciers. Ann. Glaciol., 9, 5-10.

Bogorodsky, V.V., C. R. Bentley and P.E. Gudmandsen. 1985. Radioglaciology. Dordrecht, etc., D. Reidel Publishing Co.

Copland, L., J. Harbor, M. Minner and M. Sharp. 1997. The use of borehole inclinometry in determining basal sliding and internal deformation at Haut Glacier d'Arolla, Switzerland. Ann. Glaciol., 24, 331-337.

Crabtree, M. D. 1999. The hydrological system of a temperate glacier: Falljökull, Iceland. (Ph.D. thesis, University of Leeds.)

Crabtree, M. D. and T. Murray. 1996. Measurements of water flux through glacial conduits using bore-hole acoustics. [Abstract.] EOS, 77(46), Fall Meeting Supplement, F217.

Duval, P. 1977. The role of the water content on the creep rate of polycrystalline ice. International Association of Hydrological Sciences Publication 118 (Symposium at Grenoble 1975 - Isotopes and Impurities in Snow and Ice), 29-33.

Fountain, A. G. and R.W. Jacobel. 1997. Advances in ice radar studies of a temperate alpine glacier, South Cascade Glacier, Washington, U.S.A. Ann. Glaciol., 24, 303-308.

Fountain, A. G. and J. S. Walder. 1998. Water flow through temperate glaciers. Rev. Geophys., 36(3), 299-328.

Hamran, S.-E., E. Aarholt, J. O. Hagen and P. Mo. 1996. Estimation of relative water content in a sub-polar glacier using surface-penetration radar. 7. Glaciol., 42(142), 533-537.

Hiatt, A. 1998. Englacial sediment transfer and hydrology by borehole video. (M.Sc. thesis, University of Leeds. School of Geography.)

Holmlund, P. 1988. Internal geometry and evolution of moulins, Storglaciären, Sweden. F. Glaciol., 34(117), 242-248.

Hooke, R. LeB. and V. A. Pohjola. 1994. Hydrology of a segment of a glacier situated in an overdeepening, Storglaciären, Sweden. f. Glaciol., 40(134), 140-148.

Interpex Limited. 1996. GRADIX user's manual. Golden, CO, Interpex Limited.

Jacobel, R.W. and S. K. Anderson. 1987. Interpretation of radio-echo returns from internal water bodies in Variegated Glacier, Alaska, U.S.A. 7. Glaciol., 33(115), 319-323.

Jania, J., D. Mochnacki and B. Gadek. 1996. The thermal structure of Hansbreen, a tidewater glacier in southern Spitsbergen, Svalbard. Polar Res., 15(1), 53-66.

Jezek, K. 1985. Radar measurements of borehole geometry on the Greenland and Antarctic ice sheets. Geophysics, 50(2), 242-251.

Jezek, K. C. and E. A. Roeloffs. 1983. Measurements of radar wave speeds in polar glaciers using a down-hole radar target technique. Cold Reg. Sci. Technol., 8(2), 199-208.

Lawson, D. E. 1993. Glaciohydrologic and glaciohydraulic effects on runoff and sediment yield in glacierized basins. CRREL Monogr. 93-02

Looyenga, M. 1965. Dielectric constants of heterogeneous mixture. Physica, 31 (3), 401-406.

Macheret, Yu. Ya., M.Yu. Moskalevsky and E. V. Vasilenko. 1993. Velocity of radio waves in glaciers as an indicator of their hydrothermal state, structure and regime. F. Glaciol., 39(132), 373-384. 
Murray, T., D. L. Gooch and G.W. Stuart. 1997. Structures within the surge front at Bakaninbreen, Svalbard, using ground-penetrating radar. Ann. Glaciol., 24, 122-129.

Neidell, N. S. and M.T. Taner. 1971. Semblance and other coherency measures for multichannel data. Geophysics, 36(3), 481-488.

Nicollin, F. and 7 others. 1992. An HF bi-phase shift keying radar: application to ice sounding in western Alps and Spitsbergen glaciers. IEEE Trans. Geosci. Remote Sensing, GE-30(5), 1025-1033.

Nobes, D. C., S. F. Leary, M. P. Hochstein and S. A. Henrys. 1994. Ground penetrating radar of rubble-covered glaciers: results from the Tasman and Mueller Glaciers of the Southern Alps of New Zealand. Society of Exploration Geophysicists Annual Meeting. Expanded Abstracts 64, 826-829.

Nye, J. F. 1989. The geometry of water veins and nodes in polycrystalline ice. 7. Glaciol., 35(119), 17-22.

Paren, J. G. 1970. Dielectric properties of ice. Chapter 6: Field experiments on Axel Heiberg Island. (Ph.D. thesis, University of Cambridge.)

Paterson, W. S. B. 1994. The physics of glaciers. Third edition. Oxford, etc., Elsevier.

Pohjola, V. A. 1994. TV-video observations of englacial voids in Storglaciären, Sweden. F. Glaciol., 40(135), 231-240.

Raymond, C. F. and W. D. Harrison. 1975. Some observations on the behavior of the liquid and gas phases in temperate glacier ice. F. Glaciol.,
14(71), 213-233.

Robin, G. de Q. 1975. Velocity of radio waves in ice by means of a bore-hole interferometric technique. F. Glaciol., 15(73), 151-159.

Robin, G. de Q., S. Evans and J. T. Bailey. 1969. Interpretation of radio echo sounding in polar ice sheets. Philos. Trans. R. Soc. London, Ser. A, 265(1166), 437-505.

Röthlisberger, H. 1972. Seismic exploration in cold regions. I. CRREL Monogr. II-A2a.

Sheriff, R. E. and L. P. Geldart. 1995. Exploration seismology. Cambridge, Cambridge University Press.

Shreve, R.L. 1972. Movement of water in glaciers. F. Glaciol., 11 (62), 205-214. Smith, B. M. E. and S. Evans. 1972. Radio echo sounding: absorption and scattering by water inclusion and ice lenses. F. Glaciol., 11 (61), 133-146.

Torfason, H. 1985. SE Iceland. Reykjavík, Icelandic Museum of Natural History and Iceland Geodetic Survey. (Geological map of Iceland Sheet 9.)

Vallon, M., J.-R. Petit and B. Fabre. 1976. Study of an ice core to the bedrock in the accumulation zone of an Alpine glacier. F. Glaciol., 17 (75), 13-28.

Welch, B. C., W. T. Pfeffer, J. T. Harper and N. F. Humphrey. 1998. Mapping subglacial surfaces of temperate valley glaciers by two-pass migration of a radio-echo sounding survey. F. Glaciol., 44(146), 164-170.

MS received 26 January 1999 and accepted in revised form 9 February 2000 